\title{
DYNAMIC ANALYSIS OF THE INPUT-CONTROLLED BUCK CONVERTER FED BY A PHOTOVOLTAIC ARRAY
}

\author{
Marcelo Gradella Villalva* \\ mvillalva@gmail.com
}

\author{
Ernesto Ruppert Filho* \\ ruppertafee.unicamp.br
}

${ }^{*}$ University of Campinas - UNICAMP - Brazil

\begin{abstract}
The control of the input voltage of DC-DC converters is frequently required in photovoltaic applications. In this special situation, unlike conventional converters, the output voltage is constant and the input voltage is controlled. This paper deals with the analysis and the control of the buck converter with constant output voltage and variable input.
\end{abstract}

KEYWORDS: Converter, buck, control, photovoltaic, PV.

\section{RESUMO}

O controle da tensão de entrada de conversores DC-DC é freqüentemente necessário em aplicações com energia fotovoltaica. Nesta situação especial, diferentemente do que ocorre com conversores convencionais, a tensão de saída é constante e a tensão de entrada é variável. Este artigo versa sobre a análise e o controle do conversor buck com tensão de saída constante e tensão de entrada variável.

PALAVRAS-CHAVE: Conversor, controle, fotovoltaico.

\section{INTRODUCTION}

The control of the input voltage of DC-DC converters is frequently required in photovoltaic (PV) applications. This paper analyzes the step-down buck converter fed by a PV array. In this special situation, unlike conventional converters, the

Artigo submetido em 03/09/2007

1a. Revisão em 28/12/2007

2a. Revisão em 10/10/2008

Aceito sob recomendação do Editor Associado

Prof. Enes Gonçalves Marra output voltage is constant and the input voltage is variable. Conventional converter models generally found in the literature are not applicable to this situation. Converters with input voltage control are seldom studied and this paper aims to clarify this subject.

The literature on electronic converters for PV systems is extremely wide. Depending on the characteristics of the PV system (input and output voltage levels, rated power, necessity of electrical isolation, etc) a number of converter topologies may be used. Along the past years many authors have proposed many different converters for PV applications. Some examples may be found in (Mocci and Tosi, 1989; Kjaer et al., 2002; Calais et al., 2002; Martins, 2005; Blaabjerg, 2006; Lai et al., 2008). Although the literature on this subject is enormous, it lacks information about the control of the input voltage of converters. Although this situation is quite common in PV applications, where the condition of the PV array is adjusted to meet a desired power flow (generally the maximum available instantaneous power), in most of works little or no attention is given to the control of the converter.

Converters with constant output voltage are not new. Buck, boost and other topologies have been employed in PV applications where the input is controlled instead of the output. (Koutroulis et al., 2001; Martins et al., 2004; Salas et al., 2002a) In most of works power tracking methods and other subjects regarding the PV system control are studied, but little attention is given to the converter. A PV system is generally composed of several blocks, such as a maximum power point tracking (MPPT) algorithm, voltage and current control loops, and a converter or set of cascaded converters. References (Koutroulis et al., 2001; Martins 
et al., 2002; Martins et al., 2004; Salas et al., 2002b) present systems where a PV array and a battery are interfaced with a buck converter (thus the output voltage of the converter is essentially constant) and study power tracking algorithms to adjust the condition of the PV array in order to match the desired operating point.

Few authors have investigated the input control of converters with a mathematical approach. In (Machado and Pomilio, 2004) the authors study the input control of the boost converter used in a fuel cell application. In (Xiao et al., 2007) the boost converter with input control for PV systems is analyzed. In (Cho and Cho, 1997) there is a study of the buck converter with controlled input used in a PV system. Finally, (Kislovski, 1990) makes considerations about the dynamic analysis of the buck converter employed in a battery charging system.

Although many papers bring information and even experimental results with buck-based systems, many questions still remain unanswered. These questions regard the dynamic behavior of the buck converter with constant output voltage and the design of proportional and integral compensators to control the input voltage of the converter. These subjects are very important if one considers (Kislovski, 1990), who says that if the duty cycle of buck and buck converters is the only quantity subject to modifications (i.e. the transistor 'on' and 'off' times are directly controlled by the MPPT algorithm) severe dynamic transients and excessive switch stress may take place, among other problems.

In the following sections a buck-based PV system will be modeled and three control strategies will be studied. The first strategy permits the control of the average input voltage using the transistor duty cycle as the control variable. In the second strategy the average voltage and current of the converter are controlled and two feedback control loops are employed. In the third strategy an analog inductor peak current controller and a linear feedback voltage loop are used to achieve the control of the input voltage of the converter. Hence the duty cycle is not directly controlled in order to adjust the condition of the converter. Instead, one or more feedback loops are used and the duty cycle is subject to smaller and bandwidth-limited perturbations, as (Kislovski, 1990) recommends.

\section{MODELING THE PV ARRAY}

A common circuit model for PV cells or arrays found in the literature is the electric circuit of Fig. 1, where $I_{\mathrm{pv}}$ is the photovoltaic current and $R_{\mathrm{s}}$ and $R_{\mathrm{p}}$ are the series and parallel resistances, respectively. Fig. 2 shows the simplified current vs. voltage curve of the photovoltaic array obtained from this circuit. For output voltages lower than $V_{\mathrm{mp}}$ the array behaves like a current source (segment 1 ) and for voltages greater than $V_{\mathrm{mp}}$ it becomes a voltage source (segment 2).

Arrays are composed of cascaded or paralleled photovoltaic cells and have characteristic curves similar (but not equal) to the curve of a single cell (in practice any association or array of cells is subject to partial shading, failure of cells and other external conditions that modify the behavior of the grouped devices). As noticed in Fig. 2, the photovoltaic array has a maximum power point (MPP). Ideally the array must operate at this point in order to deliver the maximum available instantaneous power. Of course, in some applications full power may not be desired in certain situations, thus another operating point will be chosen. In grid-connected systems the PV array is forced to operate at the MPP all time in order to extract and supply the grid with the maximum available instantaneous power. The parameters of the model of Fig. 1 can be obtained from Eqs. (1) and (2) with information found in datasheets supplied by PV array manufacturers, which generally provide the open-circuit voltage of the array $\left(V_{\mathrm{oc}}\right)$, the short-circuit current $\left(I_{\mathrm{sc}}\right)$, the maximumpower voltage $\left(V_{\mathrm{mp}}\right)$ and the maximum-power current $\left(I_{\mathrm{mp}}\right)$.

$$
\begin{gathered}
R_{\mathrm{s}}=\frac{V_{\mathrm{oc}}-V_{\mathrm{mp}}}{I_{\mathrm{mp}}}, R_{\mathrm{p}}=\frac{V_{\mathrm{mp}}}{I_{\mathrm{sc}}-I_{\mathrm{mp}}}-R_{\mathrm{s}} \\
I_{\mathrm{pv}}=I_{\mathrm{sc}} \frac{R_{\mathrm{s}}+R_{\mathrm{p}}}{R_{\mathrm{p}}}
\end{gathered}
$$

In many publications on photovoltaic systems the circuit of Fig. 3a is used as an array linear model. This circuit represents the line that contains the segment 1 seen in Fig. 2. However, this circuit describes the behavior of the array only in the current-source region. When $v_{\mathrm{pv}}>V_{\mathrm{mp}}$ this model does not represent the array correctly. Fig. 3b shows another linear circuit that may be an array model. This circuit originates the line that contains the segment 2 seen in Fig. 2 and describes the array in the voltage-source region of operation. This model is rare in the literature. If the array is modeled in the current-source region (line 1) the model error increases as $v_{\mathrm{pv}}>V_{\mathrm{mp}}$. Similarly, the error increases when $v_{\mathrm{pv}}<V_{\mathrm{mp}}$ if the array is modeled as a voltage source (line 2). Both models are unable to correctly represent the array in its full operating range.

\section{MODELING AND CONTROLLING THE CONVERTER}

Fig. 4 shows the circuit of the DC-DC buck converter fed by a photovoltaic (PV) array. The output voltage of the array is the variable input voltage of the converter. A storage device (e.g. battery) or a cascaded converter (e.g. DC-AC inverter) imposes to the converter a constant output voltage $V_{\mathrm{o}}$. In this 


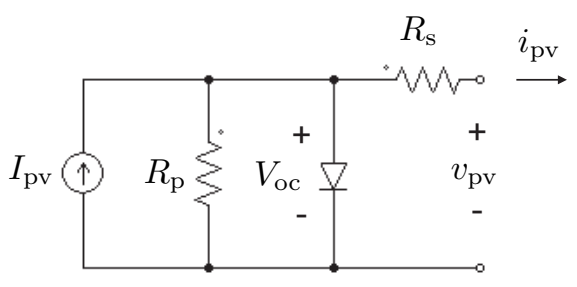

Figure 1: Equivalent circuit of the photovoltaic array.

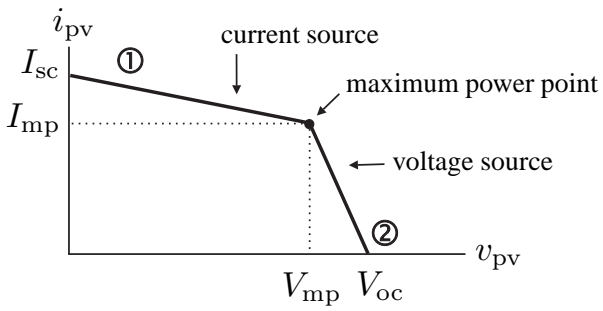

Figure 2: Simplified current vs. voltage curve of the photovoltaic array.

section linear models for this photovoltaic-buck system and feedback systems with linear compensators are designed to control the input voltage of the converter.

\subsection{Average voltage control with single feedback loop}

The first goal is to find the small-signal transfer function that describes the dynamic behavior of the input voltage of the converter of Fig. 4. The control variable is the duty cycle $d$ of the transistor, which switches at the frequency $f_{\mathrm{s}}=1 / T_{\mathrm{s}}$. The transistor is 'on' during the interval $d T_{\mathrm{s}}$ and 'off' during $(1-d) T_{\mathrm{s}}$. Considering that $f_{\mathrm{s}}$ is sufficiently high, by inspection of the circuit of Fig. 4 the state equation of the inductor current may be written as in Eq. (3). The symbol $<>$ represents the average value of the variable (voltage or current) in a switching period $T_{\mathrm{s}}$.

$$
L \frac{d<i>}{d t}=<v>d-V_{\mathrm{o}}
$$

In order to obtain the small-signal $\mathrm{AC}$ model the average variables can be expressed as a sum of DC and AC components (Erickson and Maksimovic, 2001), as shown in Eq. (4). The symbol $\sim$ represents small AC perturbations and capitalized letters represent DC steady-state values. The minus signal in Eq. (4) means that a positive duty cycle increment causes an input voltage decrement.

$$
<v>=V+\tilde{v}, d=D-\tilde{d},<i>=I+\tilde{i}
$$

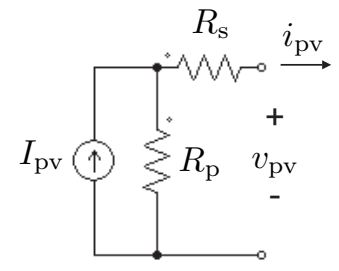

(a)

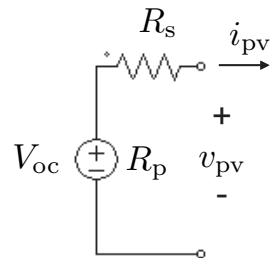

(b)
Figure 3: Photovoltaic array linear equivalent circuits. (a) Current source. (b) Voltage source.

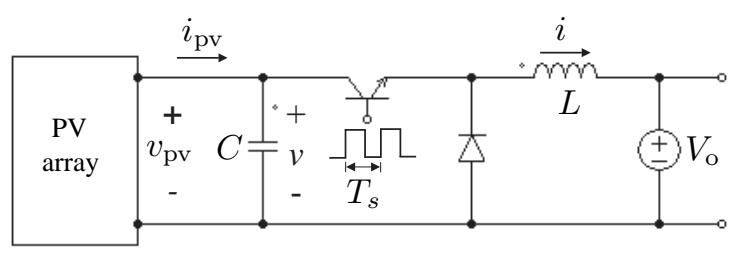

Figure 4: Buck converter with variable input and fixed output voltage fed by a photovoltaic (PV) array.

Eq. (5) is obtained from Eqs. (3) and (4). From Eq. (5), by neglecting the nonlinear product $\tilde{v} \tilde{d}$ and applying the Laplace transform, the small-signal frequency-domain state equation seen in Eq. (6) is obtained.

$$
\begin{gathered}
L \frac{d \tilde{i}}{d t}=V D+\tilde{v} D-V \tilde{d}-\tilde{v} \tilde{d}-V_{\mathrm{o}} \\
s L \tilde{i}=-V \tilde{d}+\tilde{v} D
\end{gathered}
$$

In the circuit of Fig. $4 V_{\text {eq }}$ and $R_{\text {eq }}$ are the voltage and resistance of the equivalent Thévenin's circuit of the models of Fig. 3. If the current source model (Fig. 3a) is used: $V_{\mathrm{eq}}=I_{\mathrm{pv}} R_{\mathrm{p}}$ and $R_{\mathrm{eq}}=R_{\mathrm{p}}+R_{\mathrm{s}}$. If the voltage-source model (Fig. 3b) is used: $V_{\mathrm{eq}}=V_{\mathrm{oc}}$ and $R_{\mathrm{eq}}=R_{\mathrm{s}}$. Eq. (7) is obtained by inspecting the circuit of Fig. 4. Eq. (8) is obtained from Eqs. (7) and (4). From Eq. (8), by neglecting the nonlinear product $\tilde{i} \tilde{d}$ and applying the Laplace transform, the small-signal frequency-domain state equation seen in Eq. (9) is obtained.

$$
C \frac{d<v>}{d t}=\frac{V_{\mathrm{eq}}-<v>}{R_{\mathrm{eq}}}-<i>d
$$

$$
\frac{V_{\mathrm{eq}}-V-\tilde{v}}{R_{\mathrm{eq}}}+I \tilde{d}-\tilde{i} D-I D+\tilde{i} \tilde{d}-C \frac{d \tilde{v}}{d t}=0
$$




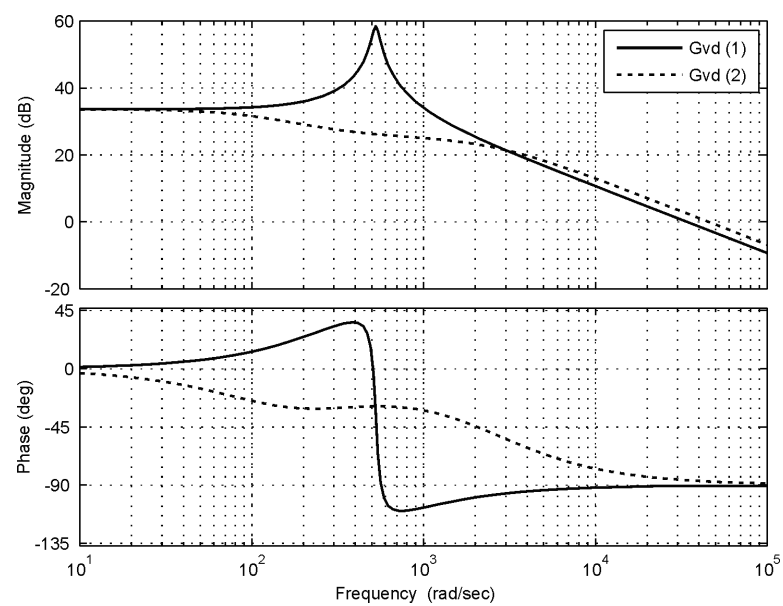

Figure 5: Bode plots of $G_{v d}(s)$ using the current source (continuous line) and voltage source (dashed line) array models.

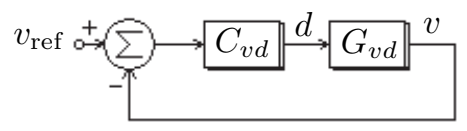

Figure 6: Feedback control of the input voltage of the converter.

$$
-\frac{\tilde{v}}{R_{\mathrm{eq}}}-s C \tilde{v}+I \tilde{d}-\tilde{i} D=0
$$

From Eqs. (6) and (9) the small-signal transfer function of Eq. (10) is obtained.

$$
G_{v d}(s)=\frac{\tilde{v}(s)}{\tilde{d}(s)}=\frac{R_{\mathrm{eq}}(V D+s L I)}{s^{2} \mathrm{R}_{\mathrm{eq}} L C+s L+D^{2} R_{\mathrm{eq}}}
$$

With a simple DC circuit analysis one finds the expressions of the steady-state values $I$ and $V$ of Eq. (11). These expressions may be substituted in Eq. (10).

$$
I=\frac{V_{\mathrm{eq}}-V}{R_{\mathrm{eq}} D}, V=\frac{V_{\mathrm{o}}}{D}
$$

Fig. 5 compares the frequency responses of $G_{v d}(s)$ when the PV array models of Figs. $3 \mathrm{a}$ and $3 \mathrm{~b}$ are used. The Bode plots of Fig. 5 were obtained with the transfer functions of the PVbuck system with the parameters and characteristics shown in Tables 1 and 2. When the current source model (Fig. 3a) is used, $G_{v d}(s)$ presents a resonance with an abrupt phase shift near $500 \mathrm{rad} / \mathrm{s}$. When the voltage source model (Fig. 3b) is
Table 1: KC200GT solar panel - nominal characteristics.

\begin{tabular}{|l|l|}
\hline Maximum power & $200 \mathrm{~W}$ \\
\hline Current at maximum power $\left(I_{\mathrm{mp}}\right)$ & $7.61 \mathrm{~A}$ \\
\hline Voltage at maximum power $\left(V_{\mathrm{mp}}\right)$ & $26.3 \mathrm{~V}$ \\
\hline Short-circuit current $\left(I_{\mathrm{sc}}\right)$ & $8.21 \mathrm{~A}$ \\
\hline Open-voltage circuit $\left(V_{\mathrm{oc}}\right)$ & $32.9 \mathrm{~V}$ \\
\hline
\end{tabular}

Table 2: Characteristics of the simulated converter.

\begin{tabular}{|l|l|}
\hline$L$ & $2 \mathrm{mH}$ \\
\hline$C$ & $450 \mu \mathrm{F}$ \\
\hline$V_{\mathrm{o}}$ & $12 \mathrm{~V}$ \\
\hline$D$ & 0.5 \\
\hline$f_{\mathrm{s}}$ & $10 \mathrm{kHz}$ \\
\hline
\end{tabular}

used, $G_{v d}(s)$ presents a low-pass response without any important characteristics.

Although neither of the models of Fig. 3 represents the PV array in its full operating range, the circuit of Fig. 3a is a suitable array linear model for the purpose of modeling the PV-buck system. By comparing the Bode plots of Fig. 5 it is possible to conclude that a feedback control system designed for the current source region of the photovoltaic array will automatically fit for the operation in the voltage-source region. In other words, the control system is designed for the worst case.

The system response with the voltage-source model offers no design difficulties because it is similar to a low-pass filter. The response with the current-source model is more complicated due to the presence of a resonance and an abrupt phase shift (Villalva and Ruppert F., 2008). Fig. 6 shows the feedback system employed in the control of the input voltage $v$ of the converter. The compensator $C_{v d}(s)$ may be a proportional-integral one designed with conventional techniques of control systems (Villalva and Ruppert F., 2007). Fig. 7 shows the frequency response of $G_{v d}(s)$ compensated with $C_{v d}(s)=0.2+20 / \mathrm{s}$, which results a crossover frequency of approximately $34000 \mathrm{rad} / \mathrm{s}$ and a margin phase of $86^{\circ}$. Low steady-state error and a fast control response may be ensured with a correct compensator design.

\subsection{Average voltage control with inner av- erage current control loop}

The second control strategy proposed here employs two small-signal transfer functions, $G_{v d}(s)$ and $G_{i d}(s)$. The current transfer function of Eq.(12) may be written from Eqs. (6) and (9). 


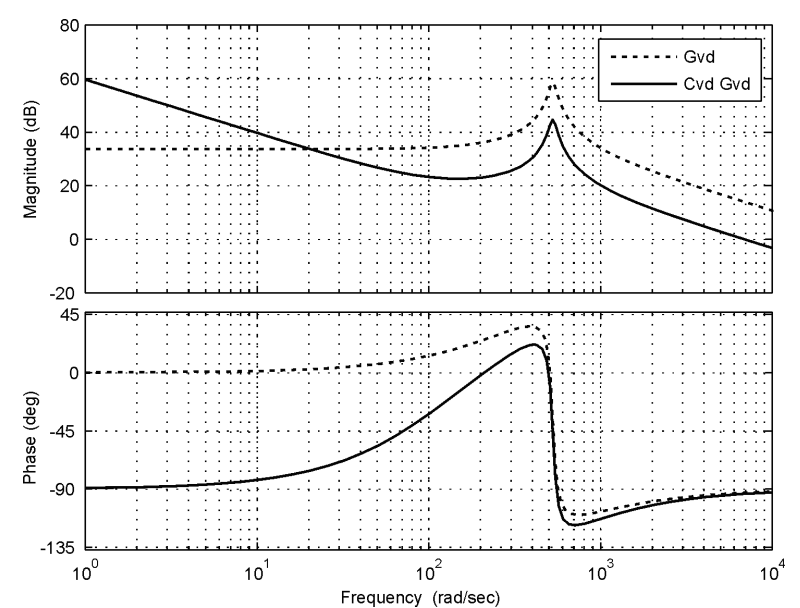

Figure 7: Bode plots of $G_{v d}(s)$ (dashed line) and of the compensated transfer function $C_{v d}(s) G_{\mathrm{vd}}(s)$ (continuous line).

$$
G_{i d}(s)=\frac{\tilde{i}(s)}{\tilde{d}(s)}=\frac{-V\left(1+s R_{\mathrm{eq}} C\right)+R_{\mathrm{eq}} D I}{s^{2} L R_{\mathrm{eq}} C+s L+R_{\mathrm{eq}} D^{2}}
$$

Fig. 8 shows the frequency response of $G_{i d}(s)$ and Fig. 9 shows its root locus. The transfer function was obtained for the system with the characteristics shown in Tables 1 and 2, considering the current-source PV array model. This system has a right-half-plane zero and its root locus is mostly on the right half-plane, which brings some difficulty for the design of the feedback control loop. The Bode plot of Fig. 8 shows that near the crossover frequency there is a phase shift of almost $180^{\circ}$. Such a marginally stable system requires special attention.

Fig. 10 shows the current control loop with the compensator $C_{i d}(s)$. This compensator may be a simple proportionalintegral one, but the proportional gain must be carefully chosen in order to set a crossover frequency with a good phase margin, keeping all system poles on the left half plane. Because the root locus is mostly on the right side of the $s$ plane, there are strong constraints in the design of the compensator $C_{i d}(s)$.

A compensator with a low proportional gain, an integrator at the origin and a zero placed at a low frequency makes this system stable. The system poles fall on the outside of the left half plane, making the system unstable, if the closed-loop crossover frequency is set above the resonance frequency of $G_{i d}(s)$. The only option to stabilize this system is keeping the magnitude at the resonance frequency bellow $0 \mathrm{~dB}$. The stabilization of the current loop results a very low current control bandwidth. Fig. 8 shows the Bode plot of $G_{i d}(s)$ compensated with $C_{i d}(s)=1.3 \cdot 10^{-4}(s+836.1) / s$.

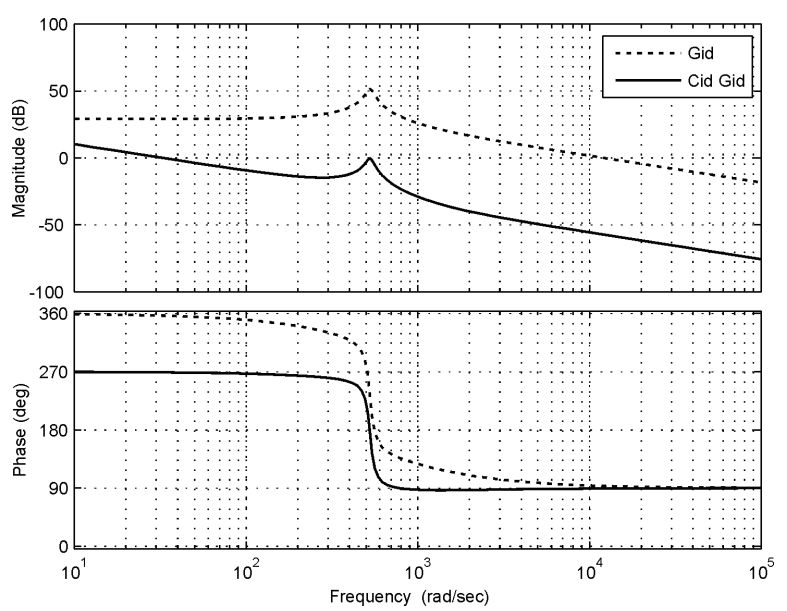

Figure 8: Bode plots of $G_{i d}(s)$ (dashed line) and of the compensated system $C_{i d}(s) G_{i d}(s)$ (continuous line).

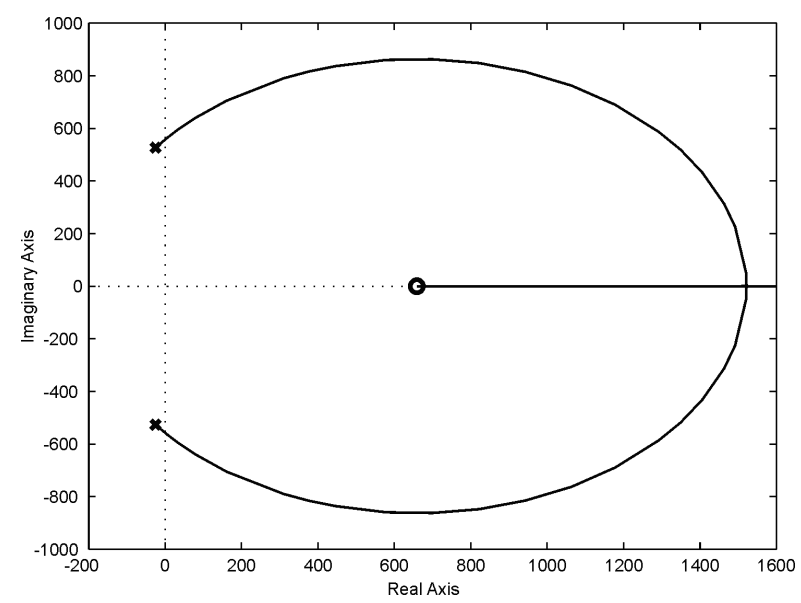

Figure 9: Root locus of $G_{i d}(s)$.

A low current-control bandwidth, however, does not mean the system will not work properly. Fig. 10 shows that an external voltage-control loop may be employed. The combination of the inner current loop and the outer voltage loop results a closed-loop system whose transient voltage response may be fast or low according to the design of the voltage compensator $C_{v i}(s)$. The voltage control may be fast although the minor current loop is inherently slow. The goal now is to design the voltage compensator $C_{v i}(s)$ used in the scheme of Fig. 10. Fig. 11 shows the frequency response of $F_{i}(s) G_{v d}(s)$ where $F_{i}(s)=C_{i d} /\left(1+C_{i d} G_{i d}\right)$. The compensator $C_{v i}(s)$ must stabilize the outer voltage loop. A simple proportional-integral compensator may be used and a large bandwidth with a sufficiently large phase margin may be easily obtained. Fig. 11 shows the Bode plot of the compensated loop transfer function $C_{v i}(s) F_{i}(s) G_{v d}(s)$, where $C_{v i}(s)=80(s+40) / s$. 


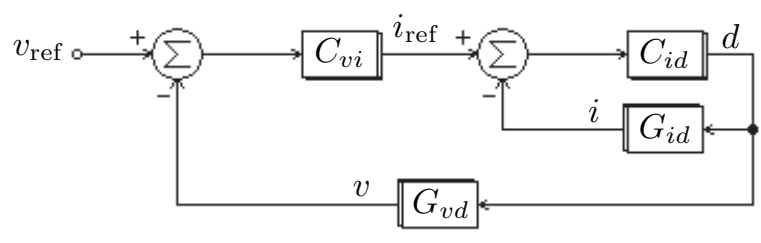

Figure 10: Control system of the input voltage with inner current loop.

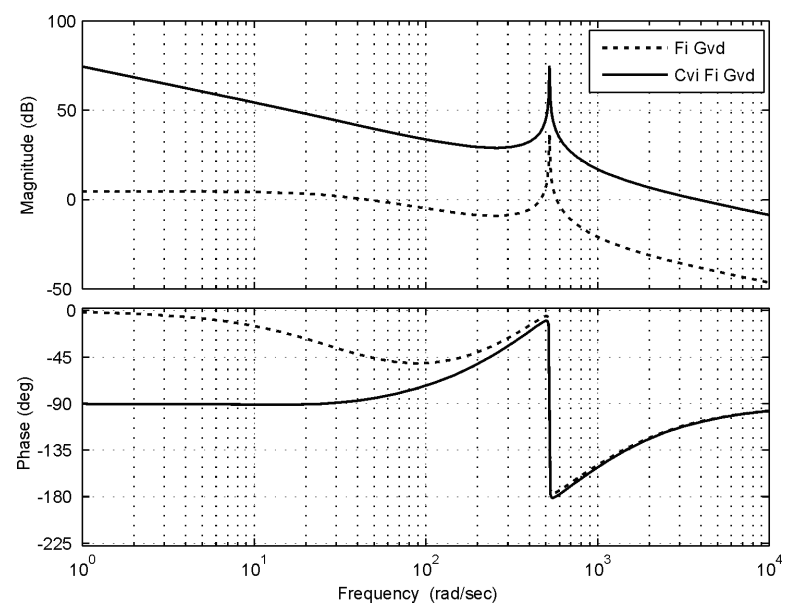

Figure 11: Frequency responses of $F_{i}(s) G_{v d}(s)$ and of $C_{v i}(s) F_{i}(s) G_{v d}(s)$.

\subsection{Voltage control with analog peak cur- rent control}

In this control strategy the inductor current is directly controlled with an analog peak current controller. The control of the input voltage is achieved with an external control loop that provides the current reference for the current controller. Fig. 12 shows the simplified scheme of the analog peak current controller. A square-wave oscillator sets the flip-flop and turns 'on' the transistor at the beginning of the switching pe$\operatorname{riod} T_{\mathrm{s}}$. The inductor current $i$ is compared with the current reference $i_{\text {ref }}$. When $i>i_{\text {ref }}$ the flip-flop is reset and the transistor is 'off' until the beginning of the next cycle.

Fig. 13 illustrates a typical inductor current waveform obtained with this control scheme. The transistor duty cycle is automatically adjusted in order to keep the inductor current near the desired reference current. When the duty cycle is greater than 0.5 this control scheme tends to become unstable (Erickson and Maksimovic, 2001; Pressman, 1997).

The stabilizing ramp signal seen in the scheme of Fig. 12 is necessary for the proper operation of the converter. The sta-

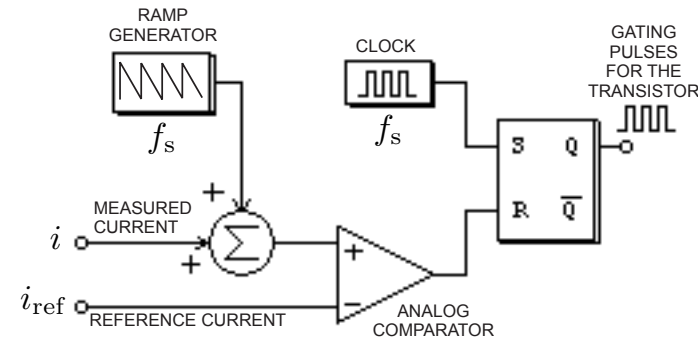

Figure 12: Analog inductor peak current controller.

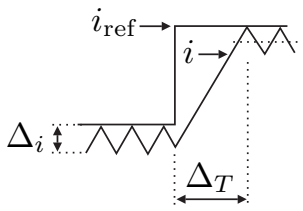

Figure 13: Waveform of the inductor current with peak current control.

bilization with the ramp signal increases the control error, as the peak of the controlled current gets farther from the reference (Erickson and Maksimovic, 2001; Pressman, 1997). However, if this control scheme is employed as the inner part of a control system with an external voltage-control loop the current error has no influence because the current reference is adjusted by the voltage compensator, thus canceling the effect of the current error.

Fig. 14 shows a strategy for controlling the input voltage of the buck converter with the peak current controller of Fig. 12. The input voltage $v$ is fed back and compared with the voltage reference $v_{\text {ref }}$. The current reference $i_{\text {ref }}$ is determined by the voltage compensator $C_{v}(s)$.

The design of the $C_{v}(s)$ compensator requires a mathematical model that describes the behavior of the converter operating with this analog current-control scheme. In order to obtain a converter model one can assume that the control of the inductor current is instantaneous. If the current has a small ripple $\Delta_{i}$ and a small error due to the stabilizing ramp, the average inductor current $\langle i\rangle$ approximately follows the reference $i_{\text {ref }}$. These assumptions are generally valid in a well-dimensioned converter with low current and voltage ripples. When the reference $i_{\text {ref }}$ is perturbed the inductor average current $\langle i\rangle$ is instantaneously adjusted except by the time $\Delta_{T}$ it takes for the inductor current to grow till its peak reaches the value of the reference signal at the $(+)$ terminal of the comparator - this is illustrated in Fig. 13.

The inductor current waveform in Fig. 13 shows that the cur- 


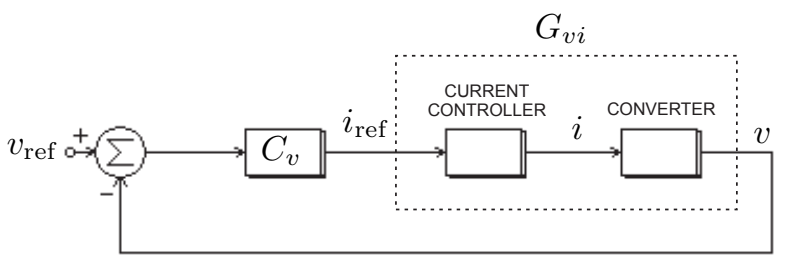

Figure 14: Voltage control employing inner system with peak current control.

rent rises linearly during the interval $\Delta_{T}$, beginning when a reference step occurs. During this interval $\left(\Delta_{T}>>T_{\mathrm{S}}\right)$ the transistor remains 'on' and the duty cycle is $d=1$. In other words, the converter is out of control during the interval $\Delta_{T}$. The transistor is simply turned 'on' and so it remains until the flip-flop receives a reset signal. This behavior is extremely nonlinear and difficult to model, since the duration of $\Delta_{T}$ depends on several variables such as the inductance $L$, the size of the reference step, and the instantaneous input voltage.

Considering that the dynamics of the current controller depends mainly on the duration of $\Delta_{T}$, which is generally small, this delay may be neglected and the peak current control scheme may be considered practically instantaneous. This simplifies the task of modeling the PV-buck system and permits to obtain the equivalent circuit of Fig. 15. Current is drained from the photovoltaic array and from the capacitor by a controlled current source. Provided that the analog current controller of Fig. 12 is capable of maintaining the inductor current regulated, the current flowing through the current source of Fig. 15 may be expressed as Eq. (13), where $D$ is the steady-state duty cycle of the transistor.

$$
<i_{\mathrm{e}}>=<i>D \approx i_{\mathrm{ref}} D
$$

With Eq. (13), using the definitions of Eq. (14), the transfer function $G_{v i}(s)$ of Eq. (15) is obtained.

$$
\begin{aligned}
& <v>=V+\tilde{v},<i>=I+\tilde{i}, \\
& <i_{\mathrm{e}}>=I_{\mathrm{e}}+\tilde{i}_{\mathrm{e}}, i_{\mathrm{ref}}=I_{\mathrm{ref}}+\tilde{i}_{\mathrm{ref}} \\
& G_{v i}(s)=\frac{\tilde{v}}{\tilde{i}_{\mathrm{ref}}}=-\frac{V_{\mathrm{eq}}-V}{I\left(1+s R_{\mathrm{eq}} C\right)}
\end{aligned}
$$

Fig. 16 shows the frequency response of the transfer function $G_{v i}(s)$ and of the compensated transfer function $C_{v}(s) G_{v i}(s) . G_{v i}(s)$ was obtained with the voltage source $\mathrm{PV}$ array model. Because the time response of the openloop system depends on the initial capacitor charge, which

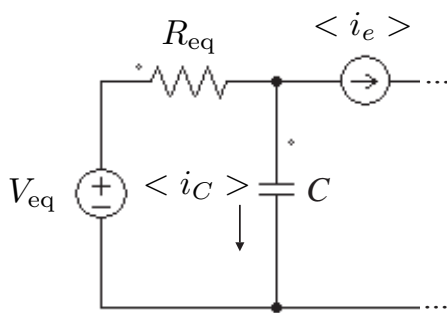

Figure 15: Equivalent circuit of the photovoltaic-buck system with peak current control.

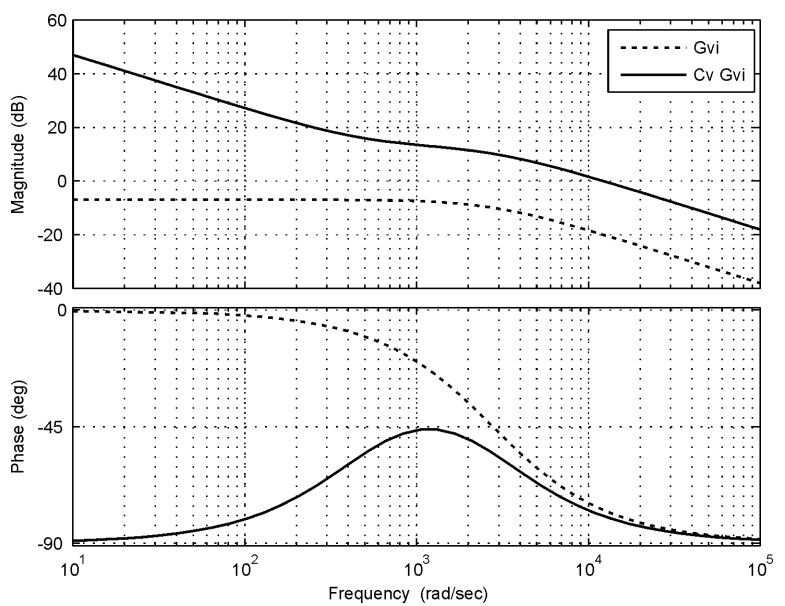

Figure 16: Frequency response of $G_{v i}(s)$ (dashed line) and of the compensated transfer function $C_{v}(s) G_{v i}(s)$ (continuous line).

depends on the open-circuit voltage of the PV array, the voltage-source model is more appropriate for the analysis of this system. The compensator $C_{v}(s)$ may be a simple proportional-integral one. This system is not critical and the compensator design is straightforward. This example uses $C_{v}(s)=(10 s+5000) / s$.

\section{SIMULATION RESULTS}

Switching converter models with the proposed control systems were simulated with the parameters of Tables 1 and 2 . These parameters were used in the previous section to obtain the transfer functions and Bode plots exhibited before. From the numerical transfer functions and from their frequency responses it was possible to design dynamic compensators required to control the input voltage of the photovoltaic-buck system. The theoretical frequency responses of the openloop and compensated systems have been presented in the previous section. These mathematical models may be validated with the analysis of the time and frequency responses 


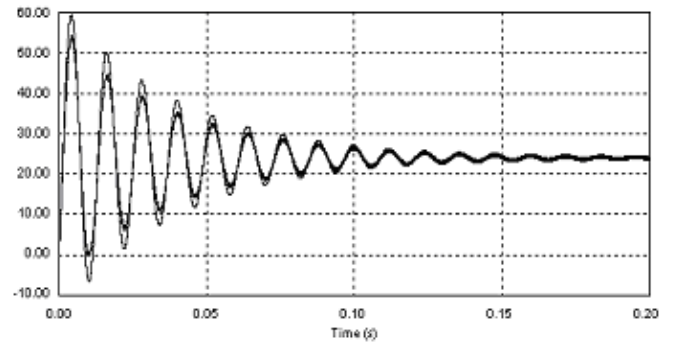

Figure 17: Step response of $G_{v d}(s)$ and input voltage of the switching buck converter with duty-cycle control.

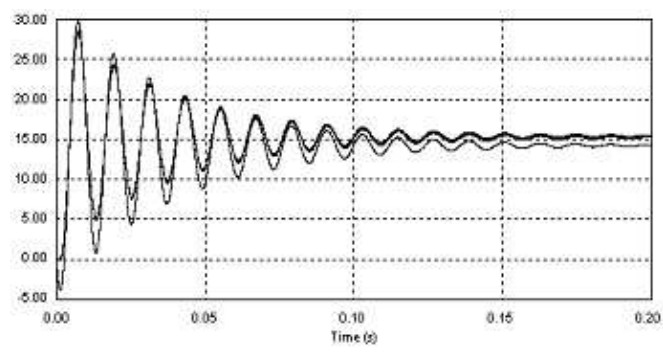

Figure 18: Step response of $G_{i d}(s)$ and inductor current of the switching buck converter with duty-cycle control.

of the simulated open-loop converter.

\section{Open-loop converter}

Fig. 17 shows the open-loop step response of the transfer function $G_{v d}(s)$ superimposed with the response of the simulated switching converter. This transfer function almost exactly represents the behavior of the switching converter regarding the duty cycle of the transistor and the capacitor voltage. Fig. 18 shows the open-loop step response of the transfer function $G_{i d}(s)$ superimposed with the response of the simulated switching converter. This transfer function represents the behavior of the switching converter regarding the duty cycle of the transistor and the inductor current.

The frequency responses of the converter were obtained by simulation in order to verify that the developed transfer functions exactly describe the behavior of the converter. Bode plots of the open-loop transfer functions $G_{v d}(s)$ and $G_{i d}(s)$ have been presented in Figs. 5 and 8, in Section 3, and now will be compared to frequency responses obtained by simulation.

The equivalent AC model of the PV-buck system is obtained in the Appendix. Fig. 30c shows the AC/DC model used in PSpice to obtain the converter frequency responses of Figs. 19 and 20. Because PSpice is unable to achieve frequency analysis of systems containing nonlinear switch-

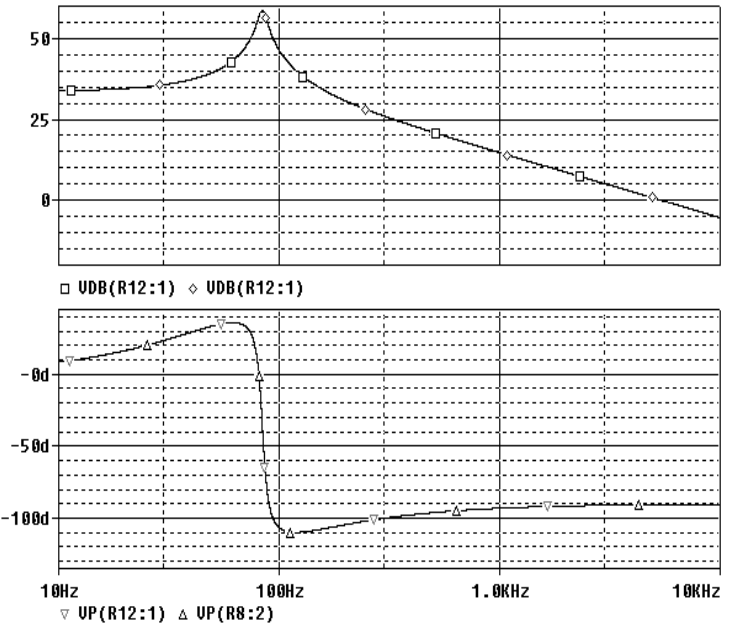

Figure 19: Frequency responses (superimposed) of $G_{v d}(s)$ and of the AC model of Fig. 30.

ing elements, an equivalent $\mathrm{AC}$ model without the nonlinear switches (transistor and diode) is necessary.

Figs. 19 and 20 show that the frequency responses of the simulated converter (equivalent AC model) exactly coincide with the responses of the theoretical transfer functions presented in Section 3. Please notice that in Figs. 19 and 20 the frequencies are expressed in $\mathrm{Hz}$, while in Section 3 the frequencies are in $\mathrm{rad} / \mathrm{s}$.

\section{Average voltage control}

Fig. 21 shows the result of the simulated switching converter with the feedback system of Fig. 6, Section 3.1. The input voltage $v$ reaches the reference with zero steady-state error.

\section{Average voltage and current control}

Fig. 22 shows the result of the converter controlled with the double feedback loop scheme of Fig. 10, Section 3.2. The input voltage $v$ of the converter reaches the reference voltage with zero steady-state error. Fig. 23 shows the behavior of the inductor current, which is also controlled in this case.

\section{Average voltage and peak current control}

Fig. 24 shows the open-loop step response of the transfer function $G_{v i}(s)$ superimposed with the response of the simulated switching converter. This transfer function approximately represents the system behavior for small and even large voltage oscillations near the nominal operating point.

The transfer function exactly describes the approximated cir- 


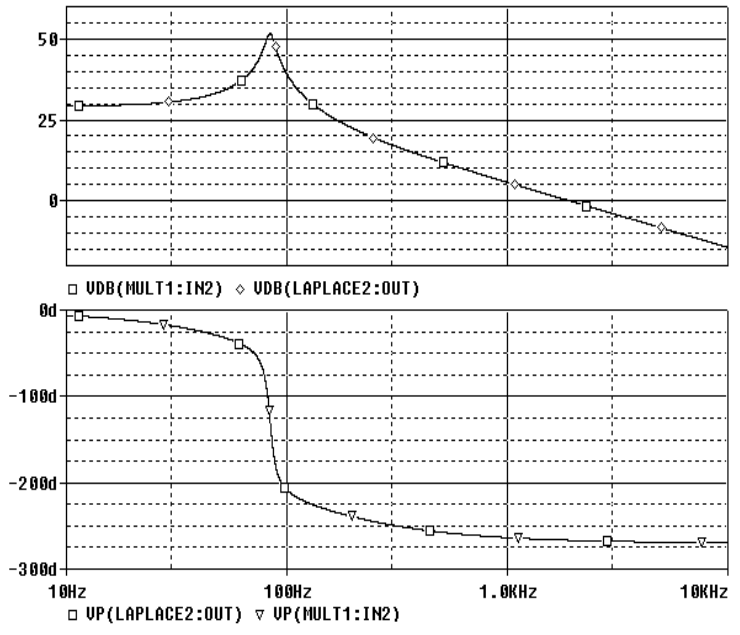

Figure 20: Frequency responses (superimposed) of $G_{i d}(s)$ and of the AC model of Fig. 30.

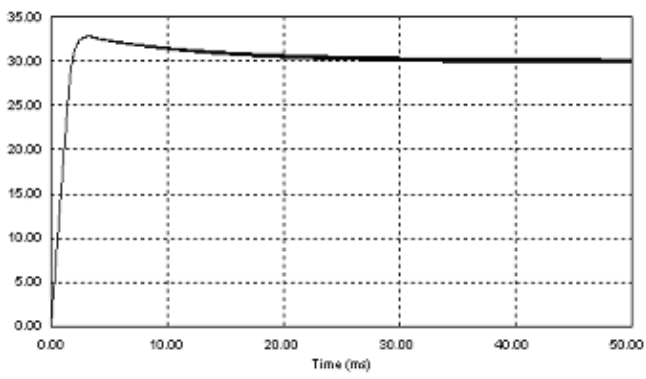

Figure 21: Input voltage $\left(v_{\text {ref }}=30 \mathrm{~V}\right)$ of the buck converter with the control system designed in Section 3.1 (single voltage loop).

cuit model of Fig. 15. The error between the responses of the transfer function and of the real system is mainly due to the approximation $\left\langle i>D \approx i_{\text {ref. }}\right.$. This system has a nonzero initial condition, since the initial capacitor charge does not depend on the existence of current flow through the controlled current source of Fig. 15. The DC value of the transfer function $G_{v i}(s)$ may not coincide with the steadystate voltage $V$.

In order to verify the validity of the converter transfer function developed in the previous section the Bode plot of the theoretical transfer function $G_{v i}(s)$ (Fig. 16) is compared with the frequency response of the equivalent circuit. Fig. 25 shows the frequency response of the model circuit of Fig. 15 superimposed with the Bode plot of $G_{v i}(s)$. Fig. 26 shows the result of the closed-loop photovoltaic-buck system operating with the current controller of Fig. 12 and the control system of Fig. 14, with the compensator designed in Section 3.3.

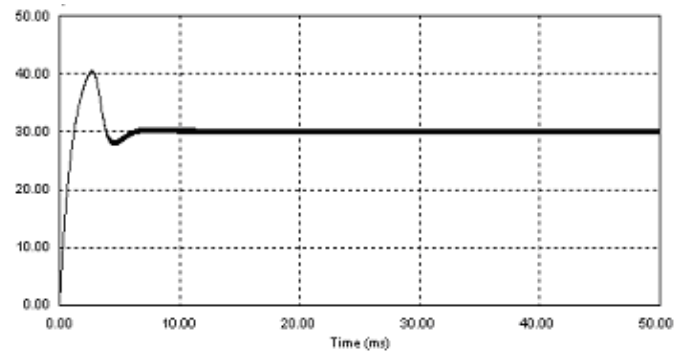

Figure 22: Input voltage $\left(v_{\text {ref }}=30 \mathrm{~V}\right)$ of the buck converter with the control system designed in Section 3.2 (voltage loop combined with inner current loop).

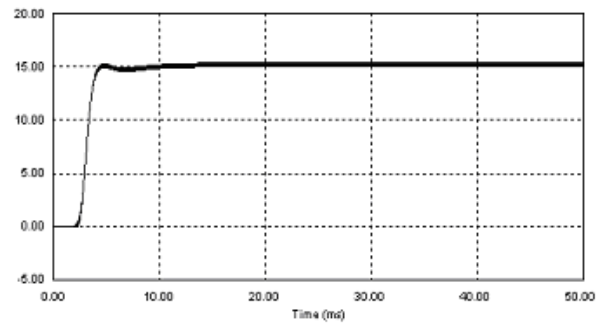

Figure 23: Inductor current of the buck converter obtained with the inner control loop designed in Section 3.2.

\section{EXPERIMENTAL RESULTS}

An experimental buck converter was built in order to validate the transfer function and the compensator developed in Section 3.1. Fig. 27 shows a picture of the experimental setup. The PV array with the parameters of Table 1 was simulated with the Agilent E4350B solar array simulator. The control system was implemented with a PIC18F452 microcontroller. The PWM frequency was set at $20 \mathrm{kHz}$ and the digital control loop was implemented with a sampling rate of $5 \mathrm{kHz}$. The characteristics of the converter are summarized in Table 3.

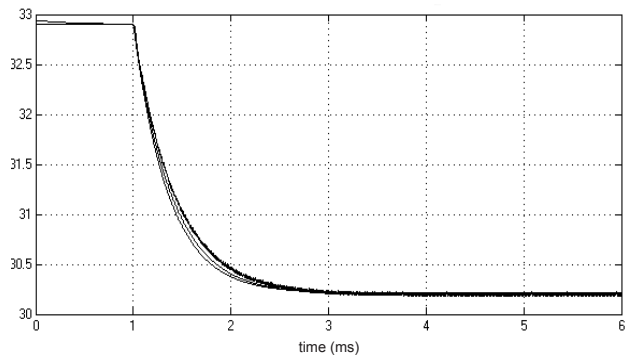

Figure 24: Responses of $G_{v i}(s)$, of the open-loop buck converter with peak current control, and of the equivalent circuit of Fig. 15 (with step input at $1 \mathrm{~ms}, i_{\text {ref }}=6 \mathrm{~A}$ ). 

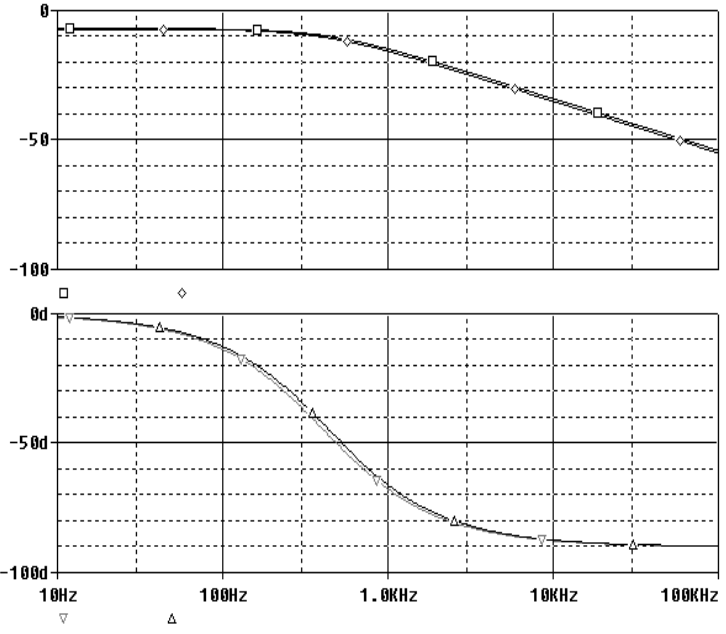

Figure 25: Frequency responses (superimposed) of $G_{v i}(s)$, and of the equivalent circuit of Fig. 15.

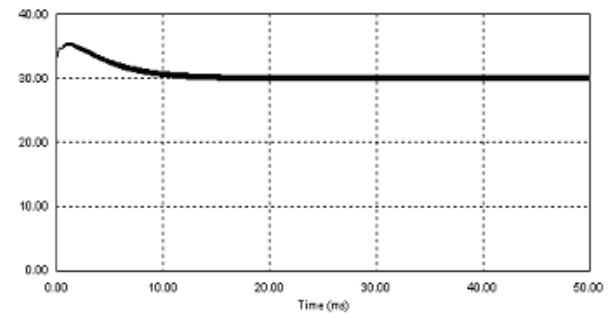

Figure 26: Input voltage $\left(v_{\text {ref }}=30 \mathrm{~V}\right)$ of the buck converter with the control system designed in Section 3.3 (voltage loop with inner peak current controller).

Fig. 28 shows the closed-loop input voltage of the experimental converter. The proportional and integral compensator has the following parameters: $k_{\mathrm{i}}=2, k_{\mathrm{p}}=500$. The feedback gain of the input voltage is $1 / 62$. For comparison, Fig. 29 shows the input voltage obtained with the simulated converter and its transfer function. The converter response differs of the transfer function response because the initial conditions are different. It is difficult to obtain in practice the zero-voltage condition for the input voltage because the capacitor is charged with the open-circuit voltage of the PV array when the converter is off.

Table 3: Characteristics of the experimental buck converter.

\begin{tabular}{|l|l|}
\hline$C$ & $1000 \mu \mathrm{F}$ \\
\hline$L$ & $5 \mathrm{mH}$ \\
\hline$f_{\mathrm{s}}$ (switching) & $20 \mathrm{kHz}$ \\
\hline$T_{\text {sample }}$ (digital control) & $200 \mu \mathrm{s}$ \\
\hline
\end{tabular}

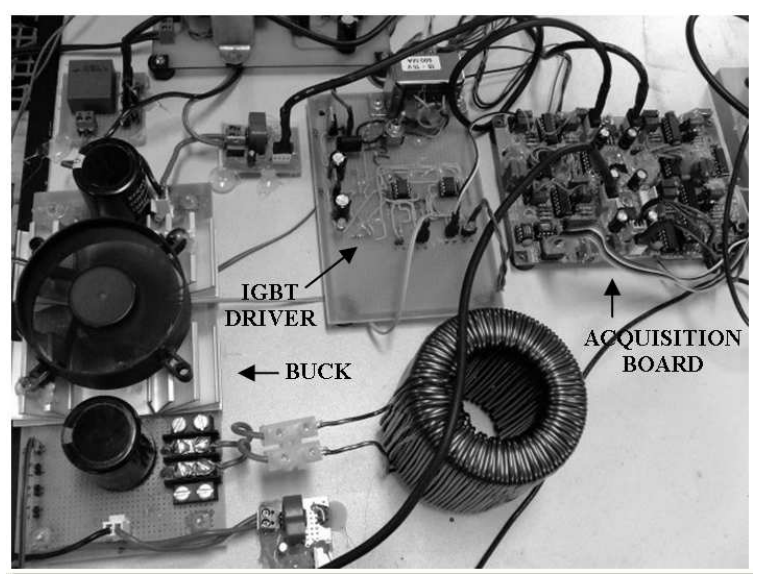

Figure 27: Experimental buck converter.

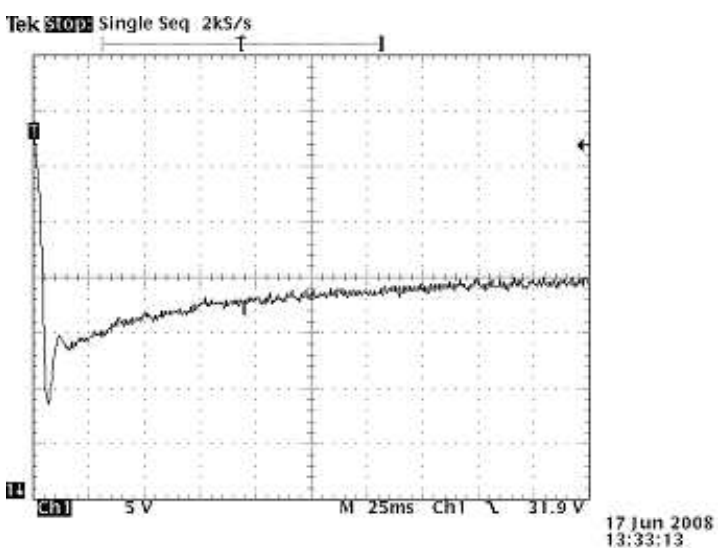

Figure 28: Closed-loop input voltage of the experimental buck converter $\left(v_{\text {ref }}=20 \mathrm{~V}\right)$.

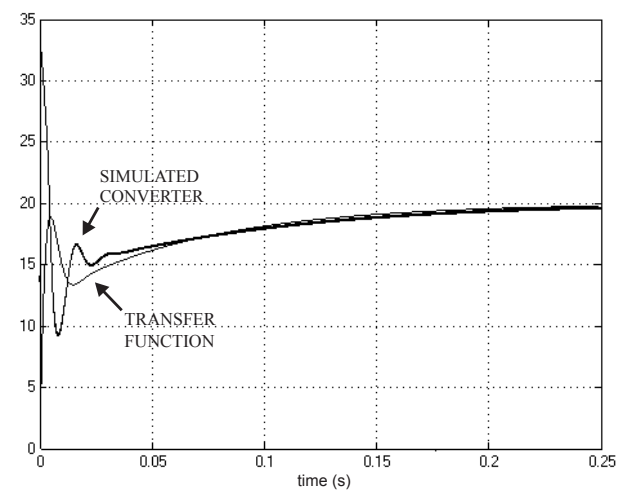

Figure 29: Closed-loop input voltage of the simulated converter $\left(v_{\text {ref }}=20 \mathrm{~V}\right)$. 

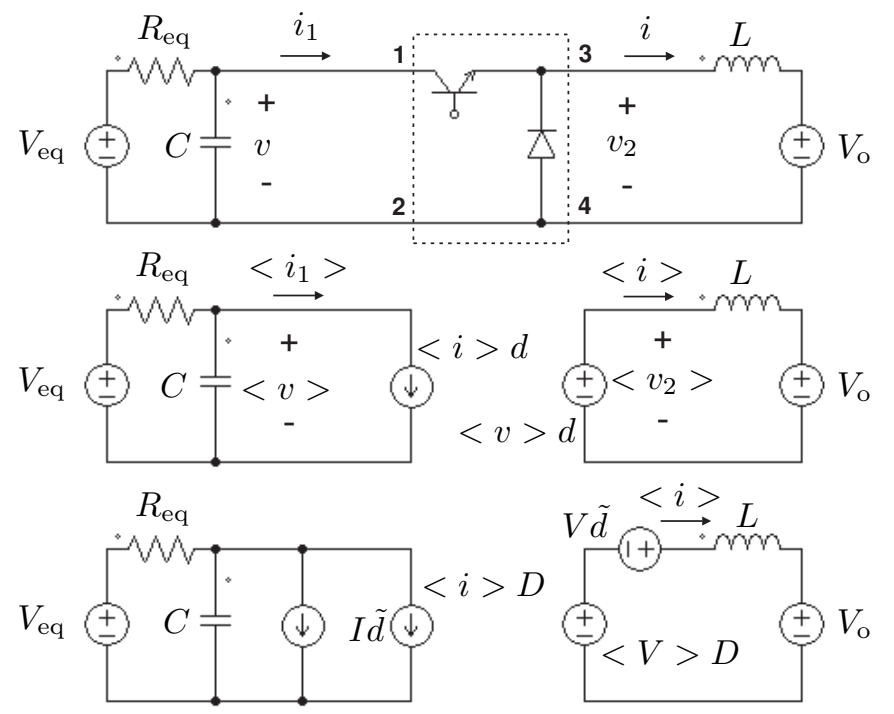

Figure 30: (a) Original PV-buck system with switching elements. (b) Nonlinear circuit with dependent sources replacing the switching elements. (c) Equivalent linear circuit with dependent sources.

\section{CONCLUSIONS}

Section 2 has demonstrated why the current-source PV array model is more convenient than the voltage-source one for the purpose of modeling this input-controlled PV system. Although neither of the models represents the array in its full operating range, the current-source model may be adopted and considered as a suitable representation of the PV array.

Section 3 has presented the development of converter transfer functions for the input voltage control of the buck converter operating with duty-cycle control (voltage mode) and with inductor peak current control (current-programmed mode). The transfer functions reveal important dynamic characteristics of the input-controlled buck converter when it is fed by a PV array. With these transfer functions it is possible to design compensators and feedback controllers for the control of the input voltage of the buck converter.

The modeling and control approaches developed in this paper are intended for the control of the input voltage of the buck converter. Many authors diverge about the advantages and disadvantages of controlling the input voltage (i.e. directly controlling the $\mathrm{PV}$ array output voltage according to a voltage reference) or the inductor current (i.e. indirectly controlling the PV output through the regulation of the buck current). This depends mainly on the kind of MPPT algorithm employed. Many works deal with the control of the output voltage of the PV array, so the input voltage of the converter is controlled in order to adjust the PV voltage. Some authors have studied control strategies that achieve the MPPT through the control of the buck inductor current (Enslin and Snyman, 1992).

Sections 3.1 and 3.2 have focused on the control of the average input voltage and inductor current of the converter. The model developed in Section 3.3 corresponds to the control of the converter with inductor peak current control.

Section 4 has presented results obtained with simulated switching converters. These results show that the proposed models and transfer functions correctly describe the dynamic behavior of the studied photovoltaic-buck system. The openloop transfer functions $G_{v d}(s), G_{i d}(s)$, and $G_{v i}(s)$ accurately describe the behavior of the converter. In order to certify that the results were correct the frequency and time responses of the open-loop transfer functions have been compared to the responses of simulated converters. The responses have almost exactly coincided both in the time and in the frequency domains. The results presented in the previous sections show that the compensators designed in Section 3 can be employed to fast and accurately control the input voltage of the DC-DC buck converter fed by a PV array.

\section{APPENDIX: EQUIVALENT AC MODEL}

In order to submit the PV-buck converter to the AC SWEEP analysis with PSpice an equivalent model without the nonlinear switching elements (i.e. the PWM modulator, the transistor and the diode) is necessary. The modulator may be simply replaced by a unit gain. The switches may be replaced by dependent current and voltage sources, following an intuitive process similar to the technique of average switch modeling (Erickson and Maksimovic, 2001). This process is valid if one assumes the transistor switching frequency is higher than the frequency of the AC components of the circuit voltages and currents. This model may be obtained from equations, following the modeling technique presented in Section 2. However, the aim here is to avoid equations and to use an exact model of the converter in order to test through simulation the validity of the equations previously obtained. The first step in the determination of the AC model is removing the transistor and the diode from the original circuit of Fig. 30a. It is easy to notice that $\left\langle v_{2}\right\rangle=\langle v>d$, so the dependent source $\langle v\rangle d$ may be placed between outputs 3 and 4, as Fig. 30b shows. Also, by simply inspecting the circuit of Fig. 30a, one can write $\left\langle i_{1}\right\rangle=<i>d$. So the current source $<i>d$ may be placed between the inputs 1 and 2, as shown in Fig. 30b. Now the nonlinear circuit of Fig. 30b may be expanded and the linear DC/AC equivalent circuit of Fig. 30c may be obtained. This step involves the definitions of Eq. (4) and Eqs. (16) - (17), where the nonlinear terms $\hat{i} \hat{d}$ and $\hat{v} \hat{d}$ are neglected. 


$$
\begin{gathered}
<i>d=(I+\tilde{i})(D-\tilde{d})= \\
=I D+\tilde{i} D-\tilde{i} \tilde{d}-I \tilde{d} \approx D(I+\tilde{i})-I \tilde{d} \\
<v>d=(V+\tilde{v})(D-\tilde{d})= \\
=V D+\tilde{v} D-\tilde{v} \tilde{d}-V \tilde{d} \approx D(V+\tilde{v})-V \tilde{d}
\end{gathered}
$$

The linear circuit of Fig. 30c represents with good accuracy the original switching circuit of Fig. 30a, both for DC and AC signals. If the DC sources $V_{\text {eq }}$ and $V_{\mathrm{o}}$ of Fig. 30c are short-circuited, the remainder circuit is the desired equivalent AC model of the PV-buck converter ready to be used in the PSpice AC SWEEP analysis.

\section{REFERENCES}

Blaabjerg, F. (2006). Power converters and control of renewable energy systems, Proc. 37th IEEE PESC.

Calais, M., Myrzik, J., Spooner, T. and Agelidis, V. (2002). Inverters for single-phase grid connected photovoltaic systems - an overview, Proc. 33rd IEEE PESC, v. 4, pp. 1995-2000.

Cho, Y.-J. and Cho, B. (1997). A digital controlled solar array regulator employing the charge control, Proc. 32nd IECEC, v. 4, pp. 2222-2227.

Enslin, J. and Snyman, D. (1992). Simplified feed-forward control of the maximum power point in PV installations, Proc. International Conference on Industrial Electronics, Control, Instrumentation, and Automation, pp. 548-553.

Erickson, R. W. and Maksimovic, D. (2001). Fundamentals of Power Electronics, Kluwer Academic Publishers.

Kislovski, A. S. (1990). Dynamic behavior of a constantfrequency buck converter power cell in a photovoltaic battery charger with a maximum power tracker, Proc. 5th IEEE APEC.

Kjaer, S., Pedersen, J. and Blaabjerg, F. (2002). Power inverter topologies for photovoltaic modules-a review, Proc. 37th IAS Industry Applications Conf., v. 2, pp. 782-788.

Koutroulis, E., Kalaitzakis, K. and Voulgaris, N. (2001). Development of a microcontroller-based, photovoltaic maximum power point tracking control system, IEEE Trans. on Power Electronics 16(1): 46-54.

Lai, J., Krein, P. and Levran, A. (2008). Power electronics for alternative energy, Professional Education Seminars Workbook. APEC.
Machado, G. and Pomilio, J. A. (2004). Controle de um sistema de geração distribuída alimentado por célula a combustível composto por conversor boost e inversor, Proc. XV CBA.

Martins, D. C. (2005). Novas perspectivas da energia solar fotovoltaica no brasil, Proc. VIII COBEP.

Martins, D. C., Weber, C. L., Gonçalves, O. H. and Andrade, A. S. (2004). PV solar energy system distribution using MPP technique, Proc. VI INDUSCON.

Martins, D., Weber, C. and Demonti, R. (2002). Photovoltaic power processing with high efficiency using maximum power ratio technique, Proc. 28th IEEE IECON, v. 2, pp. 1079-1082.

Mocci, F. and Tosi, M. (1989). Comparison of power converter technologies in photovoltaic applications, Proc. Mediterranean Electrotechnical Conf., pp. 11-15.

Pressman, A. I. (1997). Switching Power Supply Design, McGraw-Hill.

Salas, V., Manzanas, M., Lazaro, A., Barrado, A. and Olias, E. (2002a). Analysis of control strategies for solar regulators, Proc. IEEE ISIE, v. 3, pp. 936-941.

Salas, V., Manzanas, M., Lazaro, A., Barrado, A. and Olias, E. (2002b). The control strategies for photovoltaic regulators applied to stand-alone systems, Proc. 28th IEEE IECON, v. 4, pp. 3274-3279.

Villalva, M. G. and Ruppert F., E. (2007). Buck converter with variable input voltage for photovoltaic applications, Proc. IX COBEP.

Villalva, M. G. and Ruppert F., E. (2008). Input-controlled buck converter for photovoltaic applications: modeling and design, Proc. 4th IET PEMD, pp. 505-509.

Xiao, W., Dunford, W., Palmer, P. and Capel, A. (2007). Regulation of photovoltaic voltage, IEEE Trans. on Industrial Electronics 54(3): 1365-1374. 